\title{
Evaluation of a plot-scale methane emission model using eddy covariance observations and footprint modelling
}

\author{
A. Budishchev ${ }^{1}$, Y. Mi ${ }^{1}$, J. van Huissteden ${ }^{1}$, L. Belelli-Marchesini ${ }^{1}$, G. Schaepman-Strub ${ }^{2}$, F. J. W. Parmentier ${ }^{3}$, \\ G. Fratini ${ }^{4}$, A. Gallagher ${ }^{1}$, T. C. Maximov ${ }^{5,6}$, and A. J. Dolman ${ }^{1}$ \\ ${ }^{1}$ Earth and Climate Cluster, Faculty of Earth and Life Sciences, VU University Amsterdam, De Boelelaan 1085, \\ 1081 HV Amsterdam, the Netherlands \\ ${ }^{2}$ Institute of Evolutionary Biology and Environmental Studies, University of Zürich, Winterhurerstraße 190, \\ 8057, Zürich, Switzerland \\ ${ }^{3}$ Department of Physical Geography and Ecosystem Science, Lund University, Sölvegatan 12, 223 62, Lund, Sweden \\ ${ }^{4}$ LI-COR Biosciences GmbH, Siemenstraße 25a, 61352, Bad Homburg, Germany \\ ${ }^{5}$ Biogeochemical Cycles of Permafrost Ecosystems Lab, Institute for Biological Problems of Cryolithozone SB RAS, \\ 41 Lenin ave., 678891, Yakutsk, Russia \\ ${ }^{6}$ International scientific and educational center of biogeochemistry and climatology BEST (Biogeoscience Educational \\ and Scientific Trainings), Kulakovskogo 46, 677000, Yakutsk, Russia
}

Correspondence to: A. Budishchev (a.budishchev@vu.nl)

Received: 13 January 2014 - Published in Biogeosciences Discuss.: 11 March 2014

Revised: 31 July 2014 - Accepted: 4 August 2014 - Published: 3 September 2014

\begin{abstract}
Most plot-scale methane emission models - of which many have been developed in the recent past - are validated using data collected with the closed-chamber technique. This method, however, suffers from a low spatial representativeness and a poor temporal resolution. Also, during a chamber-flux measurement the air within a chamber is separated from the ambient atmosphere, which negates the influence of wind on emissions.

Additionally, some methane models are validated by upscaling fluxes based on the area-weighted averages of modelled fluxes, and by comparing those to the eddy covariance (EC) flux. This technique is rather inaccurate, as the area of upscaling might be different from the EC tower footprint, therefore introducing significant mismatch.

In this study, we present an approach to validate plot-scale methane models with EC observations using the footprintweighted average method. Our results show that the fluxes obtained by the footprint-weighted average method are of the same magnitude as the EC flux. More importantly, the temporal dynamics of the EC flux on a daily timescale are also captured $\left(r^{2}=0.7\right)$. In contrast, using the area-weighted average method yielded a low $\left(r^{2}=0.14\right)$ correlation with the EC measurements. This shows that the footprint-weighted
\end{abstract}

average method is preferable when validating methane emission models with EC fluxes for areas with a heterogeneous and irregular vegetation pattern.

\section{Introduction}

Northern wetlands are typically characterized by a heterogeneous pattern in both vegetation and hydrological conditions. This heterogeneity leads to a high spatial variation in methane $\left(\mathrm{CH}_{4}\right)$ fluxes in these ecosystems. The net exchange of $\mathrm{CH}_{4}$ in northern wetlands between the soil and the atmosphere is a balance of production and consumption processes that depend on many factors such as water table position, soil temperature, substrate availability and vegetation composition. (Shurpali et al., 1993; Bubier, 1995; Kim et al., 1998; Ström et al., 2003; Kutzbach et al., 2004; Wille et al., 2008). In continuous permafrost environments these factors are additionally affected by thawing and freezing of permafrost (Turetsky et al., 2002; Christensen et al., 2004). This complexity imposes difficulties on the quantification of methane emissions and increases the uncertainty of methane budget estimations. The use of widespread techniques such 
as the closed-chamber method and eddy covariance (EC) yields measurements over limited areas, therefore it is necessary to produce reliable models for an accurate methane budget estimation over larger areas through upscaling.

Several process-based and empirical models were developed during the last two decades to achieve that goal (Cao et al., 1996; Christensen et al., 1996; Bekki and Law, 1997; Walter et al., 2001; Zhuang et al., 2004; van Huissteden et al., 2006; Wania et al., 2010; Zhang et al., 2012). Two methods are usually employed to validate these models: (i) comparison with data, acquired with the closed-chamber method and (ii) weighing of the flux of each vegetation class in the typical fetch area of the EC tower by its areal fraction and comparison to the EC measurements.

Studies using the first method for validation rely on data sets collected with the closed-chamber method. It was shown however (Kellner et al., 2006; Sachs et al., 2008) that measurements with closed-chambers are affected by several problems such as a low spatial representativeness, low temporal resolution, inability to register transport of methane by ebullition events etc., which all increase the uncertainty of the measurements. One extreme example of low spatial representativeness was shown by Simpson et al. (1997), who discovered that an Aspen site previously reported as a methane sink, according to the data collected with closedchambers, was actually a methane source when measured with an EC system. In turn, a way to avoid low temporal resolution is the use of automatic chambers. For the measurements to be representative of the site, many such devices should be installed, which increases the costs in terms of logistics, an important factor for remote sites.

The second method solves these problems with the use of the EC technique, which typically has a high frequency of measurements (half-hourly flux calculations are becoming a de facto standard), large coverage (e.g. several hectares), and which is also a non-intrusive way of measuring ecosystem scale fluxes (Aubinet, 2000; Baldocchi, 2003; Aubinet et al., 2012). In many of the studies using this method, however, vegetation composition in the EC tower footprint is not taken into account and only areal fractions of different vegetation types of the area in a typical fetch of an EC tower are used for upscaling (Hendriks et al., 2008; Sachs et al., 2010; Zhang et al., 2012). Significant mismatches may be introduced for sites with a heterogeneous and irregular vegetation pattern when doing so - for example when the EC footprint area is covering only one or a limited group of vegetation types, leaving emissions from other types unaccounted for.

In this study, we present an evaluation of the PEATLANDVU methane emission model using EC observations collected at the Kytalyk research station in northeastern Siberia, Russia. We weigh each unit source area on a high-resolution vegetation map in the fetch of the EC tower by its contribution to the total flux (so called "footprint function" or "source weight function") with subsequent integration. This method benefits from advantages of the EC technique and also takes

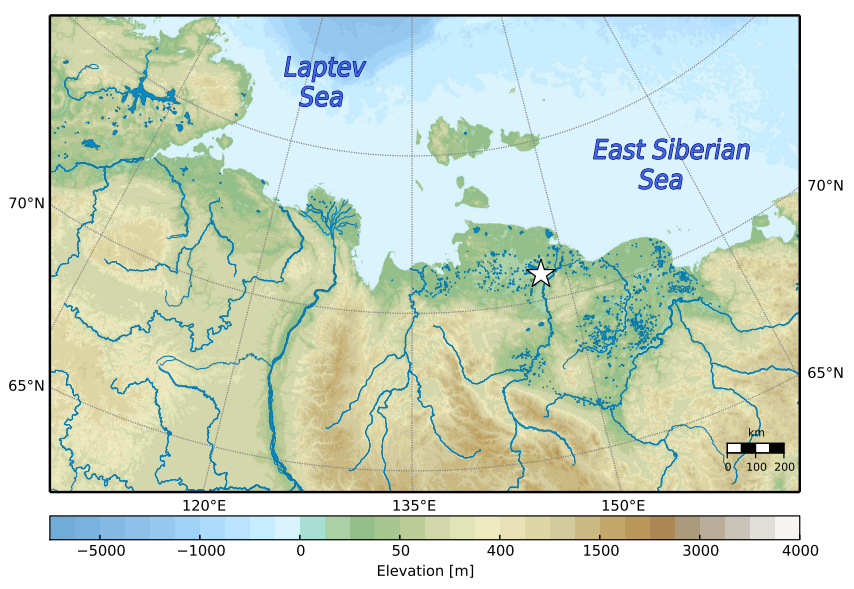

Figure 1. Elevation map of northeastern Siberia. Location of the validation site is marked with a white star. GMRT 2.4 digital elevation model (DEM) was used to create the map (Ryan et al., 2009). Blue lines represent rivers (GSHHG 2.2.4 Wessel and Smith, 1996, and Natural Earth 2.0.0 datasets).

into account the vegetation composition in the EC tower footprint.

The objectives of this study are (1) to evaluate the simulation of methane emissions from the PEATLAND-VU model with EC measurements from an ecosystem with heterogeneous vegetation, while using a footprint-weighted average approach on a daily timescale, and (2) to compare the areaweighted average to the footprint-weighted average methods.

The EC data used in the study were published by Parmentier et al. (2011). The data collected by closed chamber method were published by van Huissteden et al. (2005), van der Molen et al. (2007) and van Huissteden et al. (2009). The methane emission model was published by van Huissteden et al. (2006) and Mi et al. (2014).

\section{Materials and methods}

\subsection{Validation site}

The validation site "Kytalyk" is located in an oligotrophic tundra area in the Indigirka lowlands, Russia $\left(70.82^{\circ} \mathrm{N}\right.$, $147.50^{\circ} \mathrm{E}$ ) (Fig. 1). The area is underlain by continuous icerich permafrost. Microrelief at the surface consists of highand low-centred ice wedge polygons and low palsas (icerich mounds). The typical active layer depth during summer ranges from around $10 \mathrm{~cm}$ in dry areas to $50 \mathrm{~cm}$ in wet areas. The station is situated in a drained thaw lake basin (van der Molen et al., 2007), which is also considered a river terrace because its elevation is $1-2 \mathrm{~m}$ higher than the present river floodplain. Based on the development of the vegetation and periglacial features it can be classified as ancient (Hinkel et al., 2003), suggesting drainage at least several thousand years ago. The landscape is relatively flat, except for yedoma 


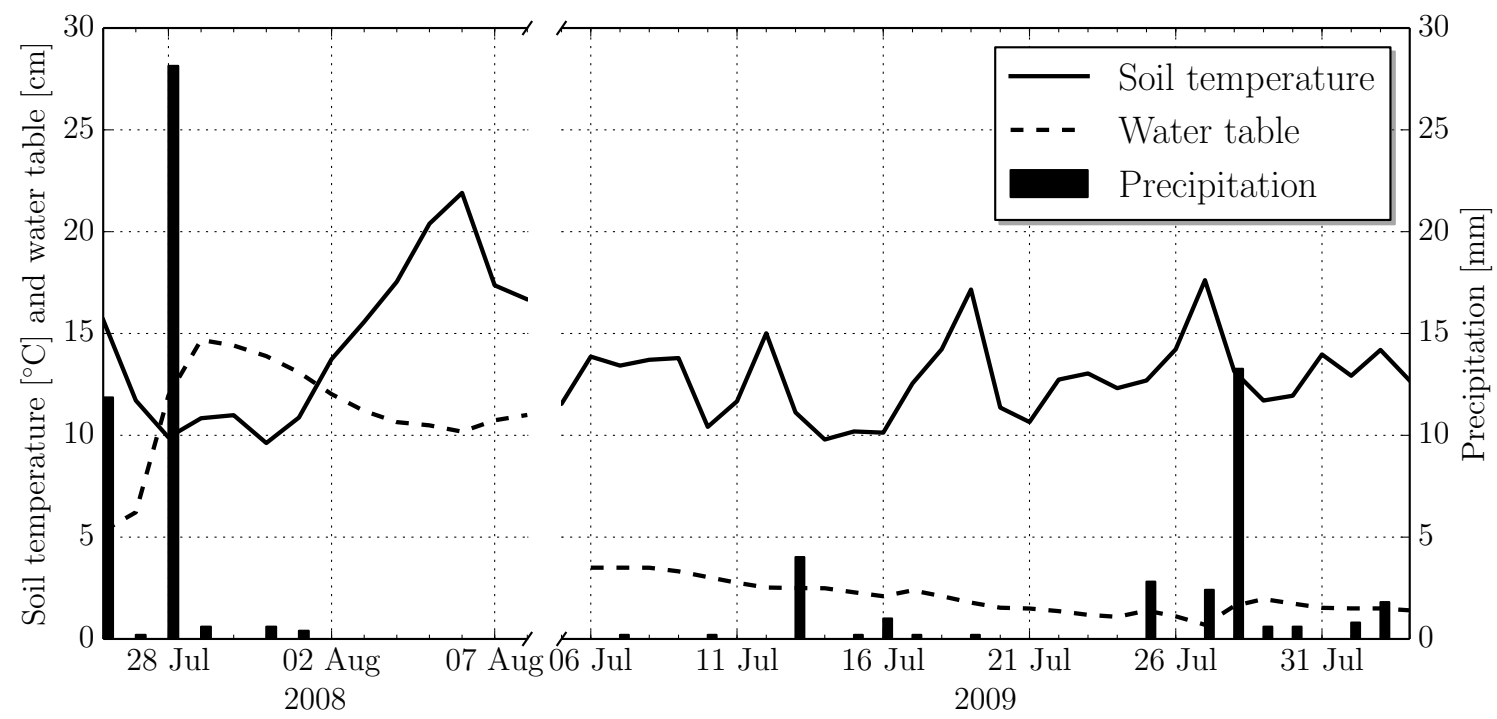

Figure 2. Temporal dynamics of daily soil temperature at $4 \mathrm{~cm}$ depth (solid line), water table position (dashed line) and daily precipitation (bars) for the EC measurement periods in 2008 and 2009.

ridges situated approximately $400 \mathrm{~m}$ to the west and east of the EC tower, which are $\sim 20 \mathrm{~m}$ higher than the terrace and a river floodplain situated nearly $250 \mathrm{~m}$ to the southeast of the EC tower, which is $\sim 2 \mathrm{~m}$ lower than the terrace.

The vegetation consists primarily of Betula nana, Eriophorum angustifolium, Eriophorum vaginatum, Salix pulchra and Sphagnum sp. on the terrace. To the west and southwest of the station there is a meander of the Berelekh river (lower course is also known as "Yelon") with a floodplain, dominated by Arctophila fulva and Arctagrostis latifolia grasses with patches of Salix pulchra on the floodplain and on the levees. The typical vegetation height on the terrace ranges from 10 to $50 \mathrm{~cm}$ and some Salix pulchra shrubs may reach $2 \mathrm{~m}$ on the levees along the river, while on the floodplain the vegetation height is typically $\sim 50 \mathrm{~cm}$.

The EC tower together with a meteo tower is installed approximately $200 \mathrm{~m}$ to the north of the research station.

\subsection{Definitions of spatial scales}

To avoid ambiguity, we provide definitions of the spatial scales that are used in this study. Plot scale is the footprint area of a chamber; it covers a single plant community. Ecosystem scale is the $1 \times 1 \mathrm{~km}$ square; it covers a mixture of several plant communities.

\subsection{Measurements of environmental parameters}

A set of environmental parameters was measured by the meteorological tower installed $5 \mathrm{~m}$ away from the EC tower. Soil temperature was measured with two profiles (type Pb107, manufactured at the VU University Amsterdam), reaching $60 \mathrm{~cm}$ depth with 10 sensors each. A short-wave radiometer (CM7b, type albedometer, Kipp \& Zonen, Delft, the Nether- lands), up- and down-facing long-wave radiometers (type PIR, The Eppley Laboratory, Newport, RI, USA) and a net radiometer (type Q7, Campbell Scientific, Logan, UT, USA) were installed. A tipping bucket rain gauge (Campbell Scientific, Logan, UT, USA) was installed to monitor precipitation. Water table position was measured manually by a piezometer on a daily basis. The daily averages of soil temperature at $4 \mathrm{~cm}$ depth, water table and daily cumulative precipitation are shown in Fig. 2.

\subsection{Eddy covariance measurements}

An ultrasonic anemometer (Gill Instruments, Lymington, UK, type R3-50) was used to measure wind speed and temperature, an open-path infra-red gas analyser (IRGA) (LICOR, Lincoln, NE, USA, type LI-7500) was used to measure water vapour and carbon dioxide concentrations, while a closed-path fast methane analyser (Los Gatos Research, Mountain View, CA, USA, type DLT-100) was used for the fast methane measurements. These measurements were conducted from 25 July to 9 August in 2008 and from 5 July to 4 August in 2009. The anemometer, the IRGA and the air intake of the methane analyser were installed at a height $\left(z_{\mathrm{m}}\right)$ of $4.7 \mathrm{~m}$. The air intake was situated $20 \mathrm{~cm}$ from the anemometer and levelled at approximately the same level as the anemometer's central point. At the other end of the tube, a vacuum scroll pump (XDS35i, Edwards, Crawley, UK) was installed. The fluxes were calculated following the EUROFLUX methodology (Aubinet, 2000) with the addition of the angle of attack dependent correction of Nakai et al. (2006). Said correction tends to increase calculated fluxes by about $2.7-5 \%$ at short vegetation sites. Zona et al. (2009) and Parmentier et al. (2011) found that fluctuations 


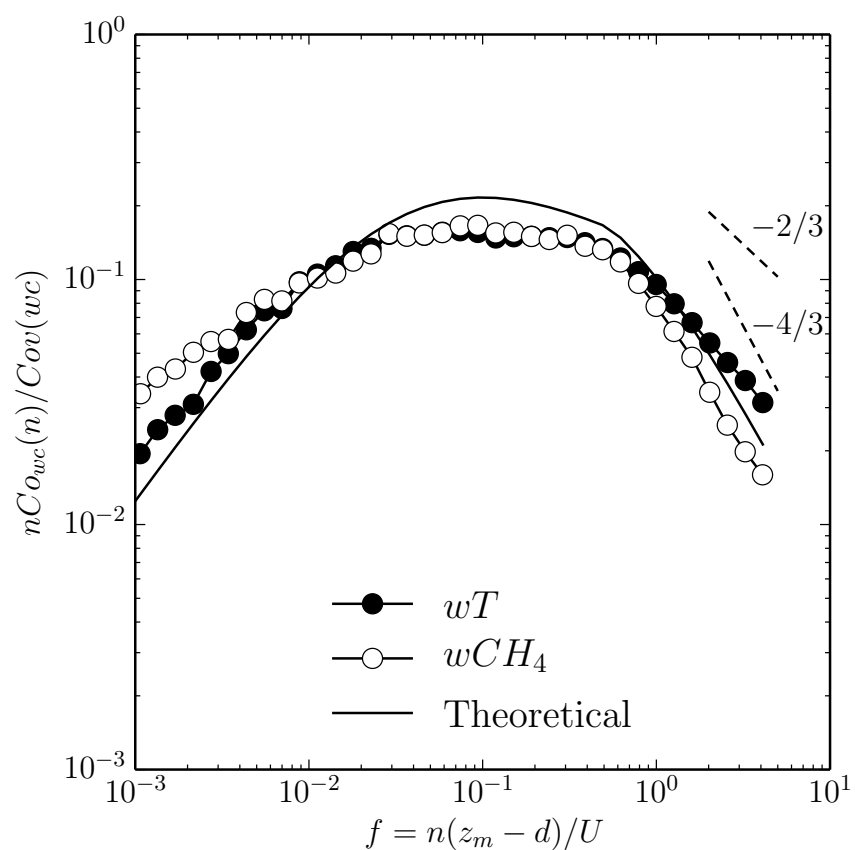

Figure 3. Frequency-binned and averaged co-spectra of sensible heat and methane fluxes for periods with unstable regime $(-650<$ $L<0)$. The $-4 / 3$ and $-2 / 3$ power laws are shown with dashed lines.

of temperature are dampened after transport through the tube and correction for water dilution is small for the same methane analyser, therefore density fluctuations correction (Webb et al., 1980) was not applied to the methane fluxes. The fluxes were calculated using custom-made software written in MATLAB (2008a, The Mathworks Inc., Natick, MA, USA) and developed by Michiel van der Molen. For a detailed description of the EC setup and flux calculation see Parmentier et al. (2011).

As reported by Parmentier et al. (2011), the EC measurements during periods when the wind is blowing from the direction of the research station $\left(155^{\circ}>\alpha<195^{\circ}\right)$ might be disturbed. Since there are no artificial methane sinks, any disturbance would lead to elevated emissions. However, we did not find a significant difference in magnitude of concentrations and fluxes coming from this wind sector. Moreover, all the potential artificial methane sources are point-like and located at the distance of at least $200 \mathrm{~m}$, therefore the footprint function value for these locations would be very small, decreasing the artificial component of the measured fluxes. Thus, the screening for this wind sector was not applied.

An energy balance analysis of the system was performed by van der Molen et al. (2007) and Parmentier et al. (2011), who found a good $1: 1(99.8 \%)$ energy balance closure.

Figure 3 shows frequency-binned and averaged co-spectra of sensible heat and methane fluxes for both measurement periods. The co-spectral shapes generally follow their respective archetypes. The inertial subrange decays according to
Table 1. Vegetation classification and fractional area.

\begin{tabular}{lrr}
\hline Mapped vegetation type & $\begin{array}{r}\text { Fractional } \\
\text { area [\%] }\end{array}$ & $\begin{array}{r}\text { Assigned } \\
\text { class }\end{array}$ \\
\hline Salix pulchra & 6.47 & TD1 \\
Soil & 0.53 & TD1 \\
Eriophorum vaginatum and Betula nana & 48.60 & TD1 \\
Eriophorum angustifolium and Carex sp. & 7.01 & TW1 \\
Arctophila fulva and Arctagrostis latifolia & $9.7 / 7.54$ & TW1/FW2 \\
Sphagnum sp. & 12.29 & TW4 \\
River and lakes & 5.66 & N/A \\
Unclassified & 2.18 & N/A \\
\hline
\end{tabular}

a $-2 / 3$ power law. We cannot explain this behaviour of the EC system - however, when applying frequency response corrections, the correction factor is calculated using model co-spectra defined by Moore (1986); Kaimal et al. (1972); Høstrup (1981), therefore the effect of the observed elevated spectral power in inertial subrange is compensated for at the cost of increased uncertainty.

The good energy balance closure and expected shapes of co-spectral densities of sensible heat and methane fluxes indicate that the calculated fluxes are of high quality and can be used as a reference in our analysis.

Since the PEATLAND-VU model works only on a daily timescale, half-hourly measurements were down-sampled to daily averages, if more than 35 measurements were available ( $\sim 73 \%$ or more measurements) per day. Using this method for averaging, 5 days were discarded in total $-25,28$ July and 9 August in 2008 and 5 July and 4 August in 2009.

\subsection{Closed-chamber measurements}

Measurements of methane fluxes with the manual closedchamber technique were conducted from 31 July until $7 \mathrm{Au}-$ gust in 2008 and 11 July until 1 August in 2009 along transects 1 and 2 (Fig. 4). A round transparent chamber and a photo-acoustic gas monitor (model 1312, Innova AirTech Instruments, Ballerup, Denmark) were used to measure methane concentrations in the chamber with an interval of $2 \mathrm{~min}$ and a total duration of $8 \mathrm{~min}$. The chamber was shielded from the sun during the measurements to prevent large temperature increases. A linear regression was then applied to these data to calculate the methane fluxes. A quality check according to van Huissteden et al. (2005) was performed, and data which showed chamber leakage or ebullition spikes were discarded. Together with the flux measurements, soil temperature at $10 \mathrm{~cm}$ depth, active layer depth and water table position were recorded.

\subsection{Vegetation map}

A GeoEye-1 (high-resolution Earth observation satellite) image acquired on 19 August 2010 was used to produce a high-resolution vegetation map. A maximum likelihood 


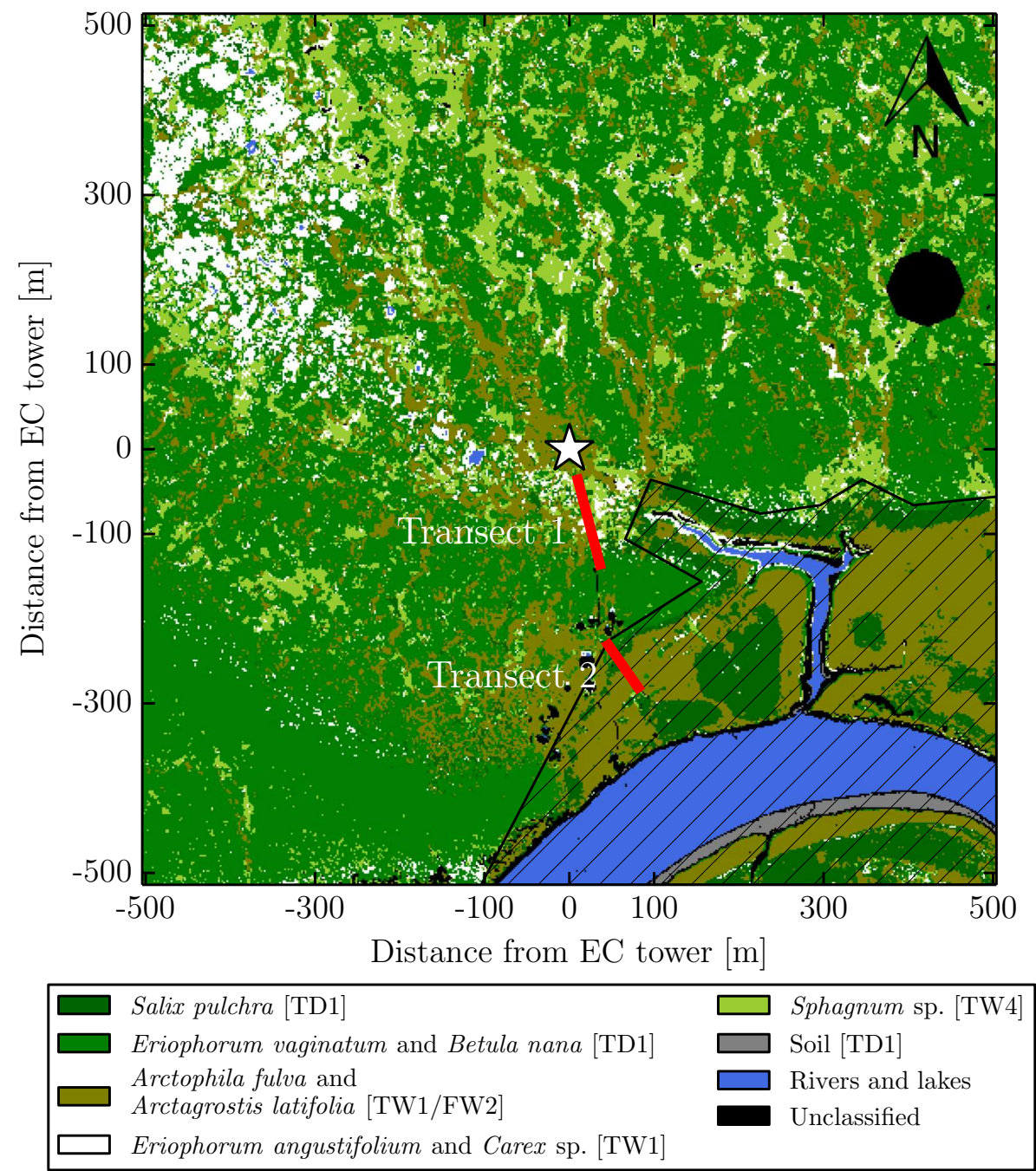

Figure 4. Vegetation map. Hatched area represents the area where the Arctophila fulva and Arctagrostis latifolia vegetation type was assigned to the FW2 class. Location of the EC tower is marked with a white star. Chamber flux measurements for classes TW1, TW4 and TD1 were done along Transect 1, and for FW2 class along Transect 2.

classification algorithm implemented in ENVI 4.8 (ITT Visual Information Solutions, Boulder, USA) was used for the classification, and 31 georeferenced plots with known vegetation and land cover type were used as training areas for five vegetation types. The resulting resolution of the map is $2 \mathrm{~m}$. Because the model uses the classification of van Huissteden et al. (2005), a reclassification of the vegetation map was done to match the model's output (see Table 1). An Arctophila fulva and Arctagrostis latifolia class was divided into two different subclasses - TW1 on the terrace and FW2 on the floodplain (Fig. 4). As shown previously (van Huissteden et al., 2005), the floodplain may have significantly higher methane emissions, therefore using either the TW1 or FW2 class for both terrace and floodplain would yield biased results.
The River and Lakes class, which comprises nearly $6 \%$ of the map, had no measurements of methane fluxes. There are very few studies that provide some insight into methane emissions from Arctic rivers. One study (Kling et al., 1992) reported $0.36 \mathrm{mmol} \mathrm{m}^{-2} \mathrm{~d}^{-1}\left(0.24 \mathrm{mg} \mathrm{CH}_{4} \mathrm{~m}^{-2} \mathrm{~h}^{-1}\right)$ from Kuparuk River, Alaska, USA. A recent study by Striegl et al. (2012) showed a similar emission estimate of $0.39 \mathrm{mmol} \mathrm{m}^{-2} \mathrm{~d}^{-1}\left(0.26 \mathrm{mg} \mathrm{CH}_{4} \mathrm{~m}^{-2} \mathrm{~h}^{-1}\right)$ from the middle course (Arctic part) of the Yukon river, Alaska, USA. We take an average of $0.375 \mathrm{mmol} \mathrm{m}^{-2} \mathrm{~d}^{-1}\left(0.25 \mathrm{mg} \mathrm{CH}_{4} \mathrm{~m}^{-2} \mathrm{~h}^{-1}\right)$ and assume this emission as constant for the class throughout the EC measurement periods for both years. The error introduced by this assumption is bound to be small as this class only covers $6 \%$ of the map. 
There are only $2 \%$ of the pixels on the map left unclassified due to cloud cover in the original image, which has only a minor impact on the final figure.

It is important to note that high-resolution mapping of such ecosystems is essential for upscaling methane fluxes with any upscaling method (Riutta et al., 2007; Schrier-Uijl et al., 2010; Sachs et al., 2010).

\subsection{PEATLAND-VU model description}

The latest version of the PEATLAND-VU model was used in this study (van Huissteden et al., 2006). It is a process-based, plot-scale model developed for the quantification of $\mathrm{CO}_{2}$ and $\mathrm{CH}_{4}$ fluxes from wetlands. $\mathrm{A} \mathrm{CH}_{4}$ sub-model is implemented following Walter and Heimann (2000) for production, oxidation and transport of methane, and for addition of organic material to the root zone. Changes to the model include the addition of a water table model to calculate water table from precipitation and evaporation (Granberg et al., 1999; Yurova et al., 2007) and a photosynthesis module for the estimation of gross primary production (GPP) (Haxeltine et al., 1996; Sitch et al., 2003).

Air temperature, evapotranspiration, precipitation and snow depth were used as input variables for the model. The data were collected at the site's meteorological tower on a half-hourly temporal scale and gaps were filled with the data collected at the Chokurdakh airport meteorological station, located $30 \mathrm{~km}$ away from the study area. The inputs were then resampled to a daily timescale. The model was parameterized per vegetation type and the same input variables were used to model $\mathrm{CH}_{4}$ fluxes from different vegetation types. The model was calibrated with data collected with the closed-chamber method during the summer periods from 2004 to 2010 excluding 2007 data from the floodplain. The model operates with classification defined by van Huissteden et al. (2005) and has daily temporal resolution. For a detailed description of the model see Mi et al. (2014).

\subsection{Footprint model description}

For modelling of the EC tower footprints we used the model by Kormann and Meixner (2001)

$$
\begin{aligned}
\phi(x, y)= & \frac{1}{\sqrt{2 \pi} \sigma(x)} \exp \left(\frac{-y^{2}}{2 \sigma^{2}(x)}\right) \\
& \times \frac{1}{\Gamma(\mu)} \frac{\xi^{\mu}}{x^{1+\mu}} \exp \left(\frac{-\xi}{x}\right),
\end{aligned}
$$

where $\phi(x, y)$ is the 2-D footprint function, $\sigma(x)=\sigma_{v} \times x / \bar{u}$ is the cross-wind dispersion, $\bar{u}$ is the effective plume velocity, $\sigma_{v}$ is the constant crosswind fluctuation, $\xi$ the flux length scale, $\mu=(1+m) / r$ is a constant, $r=2+m-n$ the shape factor, with $m$ the exponent of the wind velocity power law, and $n$ the exponent of the eddy diffusivity power law.

The model uses a gamma distribution for along-wind and a Gaussian distribution for cross-wind footprint estimation.
Because the model is based on the Monin-Obukhov similarity theory, which only holds in the atmospheric stability regimes defined by $-1<\varsigma<+1$ (where $\varsigma=z_{\mathrm{m}} / L$, and $L$ the Monin-Obukhov length), we only used flux data and footprint estimations of periods characterized by this stability regime in our analysis. This resulted in a total removal of 73 unstable and 89 stable cases.

The 2-D footprint estimations provided by the model on a half-hourly basis were then averaged to get daily means. After all mentioned quality screenings, 40 daily means were available for further analysis.

Mean daily 2-D footprint estimates were integrated within the domain defined by the available vegetation map. It was found that $56 \%$ of the time the integral $(\Omega)$ exceeded the value of 0.85 - with a minimum of 0.78 - suggesting that the vegetation map is large enough for the purposes of our analysis.

Figure 5 shows the flux footprint climatology of the EC tower. The peak value of the footprint function typically stays at a $\sim 51 \mathrm{~m}$ distance from the tower and the average $80 \% \mathrm{cu}-$ mulative flux distance is $\sim 377 \mathrm{~m}$. The peak location and the $80 \%$ cumulative flux distance are distributed evenly across the wind directions, except for the S-E direction where the $80 \%$ cumulative flux distance extends to more than $500 \mathrm{~m}$ due to higher occurrences of stable atmospheric regime. The winds mainly come from the north and east with speeds of 2 to $6 \mathrm{~ms}^{-1}$.

For the footprint model to be applicable to the site, it is necessary to assume that while the vegetation pattern is heterogeneous, and that the surface is relatively homogeneous in terms of vegetation height, so that momentum flux is not disturbed (Forbrich et al., 2011). Considering the vegetation height of the site and the measurement height of EC system, we assume this disturbance to be negligible.

\subsection{Evaluation}

To compare fluxes modelled for the different classes (TD1, TW1, TW4, FW2 and River and Lakes in this study) to the EC flux, two methods were applied.

\subsubsection{Area-weighted average}

Upscaling with this method was done by calculating the areal fractions of the vegetation types on the vegetation map and multiplying them by the emission factor for that class. Subsequently, these area-weighted (AW) emissions were summed:

$F_{\mathrm{AW}}=\sum_{i=1}^{5} f_{i} F_{i}$,

where $F_{\mathrm{AW}}$ is the ecosystem scale methane flux, $f_{i}$ the fraction on the map (Table 1) and $F_{i}$ the methane emission of the class. Numbers $i=1-5$ indicate classes TD1, TW1, TW4, FW2, and River and Lakes. This method was used in numerous studies in the past and is considered to yield a good match 


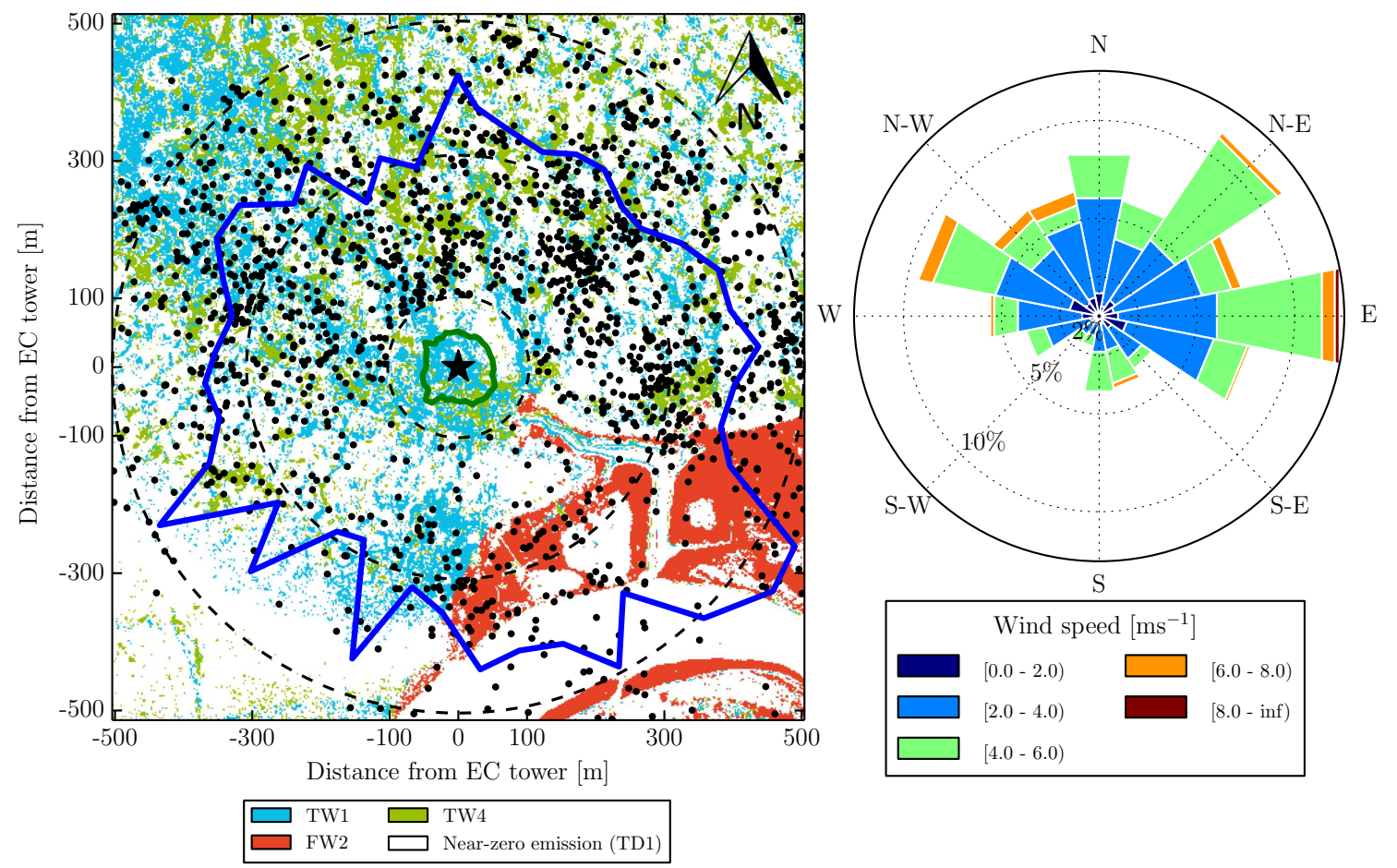

Figure 5. Flux footprint climatology of the EC methane measurement periods (left) and wind rose (right). Blue contour line shows average $80 \%$ cumulative flux distance and dark green contour line shows average location of the footprint function peak value for both EC methane measurement periods binned by wind direction. Black dots show the half-hourly $80 \%$ cumulative flux distances. Location of the EC tower is marked with a black star. Dashed concentric circles show the 100, 300 and $500 \mathrm{~m}$ distances to the EC tower. The underlying image shows spatial distribution of the vegetation classes for which methane fluxes were modelled. The wind rose shows the distribution of winds during 2008 and 2009 measurement campaigns.

on a monthly to seasonal scale (van der Molen et al., 2007; Parmentier et al., 2011; Zhang et al., 2012). The upscaled fluxes were then compared to the EC measurements.

\subsubsection{Footprint-weighted average}

To derive a quantity that could be directly compared to measured EC fluxes, we calculated the footprint integrated methane flux with the footprint-weighted (FW) average, after substitution of classes with their respective emission factors on the vegetation map.

Every pixel on this methane emissions map was then weighted with the daily averaged 2-D footprint function. Subsequently, weighted emission factors from every pixel were summed. To compensate for a limitation of footprint functions by the vegetation map ( $\Omega<1$ situations), the fluxes were normalized by $\Omega$ (Eq. 3). This operation was needed to make individual flux estimates directly comparable, and it assumes that the vegetation pattern outside the vegetation map does not differ significantly from the mapped one:

$F_{\mathrm{FW}}=\left(\sum_{y=1}^{\mathrm{Y}} \sum_{x=1}^{\mathrm{X}} \phi(x, y) F(x, y) A_{\mathrm{res}}\right) / \Omega$, where $F_{\mathrm{FW}}$ represents the footprint integrated methane flux, $\phi(x, y)$ the footprint (or source area) weight value at point $(x, y), F(x, y)$ the methane emission rate at point $(x, y), A_{\text {res }}$ the area of a pixel and $X$ and $Y$ the dimensions of the vegetation map. A similar approach was used by Forbrich et al. (2011) for downscaling purposes. The fluxes calculated with this method were then compared to the EC measurements.

\subsection{Similarity between the evaluation methods}

The two evaluation methods - even though different - share some similarities. As modelled footprints cover only a portion of a vegetation map, one may think of the FW method as a subset of the AW method, which covers the whole vegetation map. In this regard, it is possible to imagine the AW method as the FW method with a footprint of constant shape, such that the contribution of each vegetation type equals the fractional area of these types on a vegetation map.

To show this, we calculate the difference between the fluxes calculated by the two methods (Eq. 4) and the "vegetation composition difference" (Eq. 5), which shows the sum of absolute differences between the total footprint function of the emitting class normalised by $\Omega$ and fractional cover of 

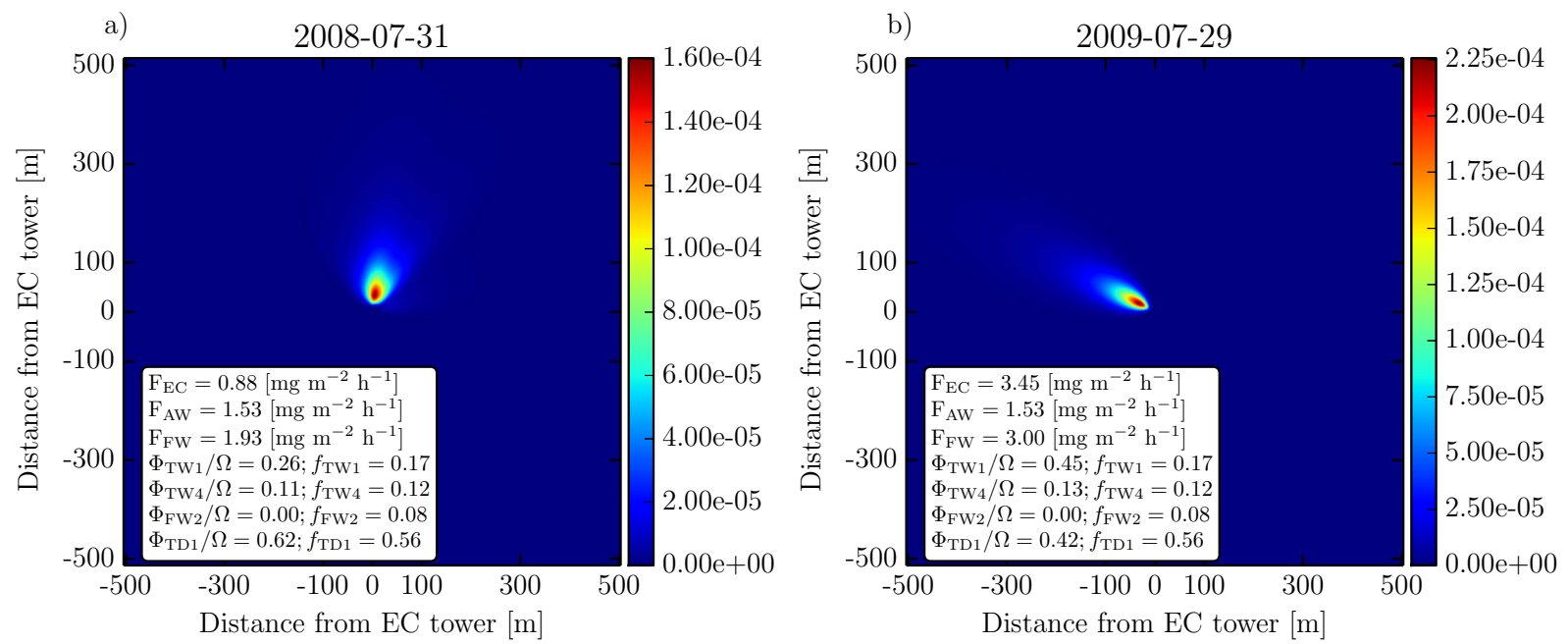

Figure 6. Examples of the modelled footprints for 31 July 2008 (a) and 29 July 2009 (b). The images show 2-D distributions of the footprint functions. The inset text boxes show values of the measured EC flux $\left(F_{\mathrm{EC}}\right)$, calculated fluxes $\left(F_{\mathrm{AW}}\right.$ and $\left.F_{\mathrm{FW}}\right)$, integrated footprint function per vegetation type normalized by $\Omega\left(\Phi_{i}\right)$ and fractional areas of vegetation types $\left(f_{i}\right)$.
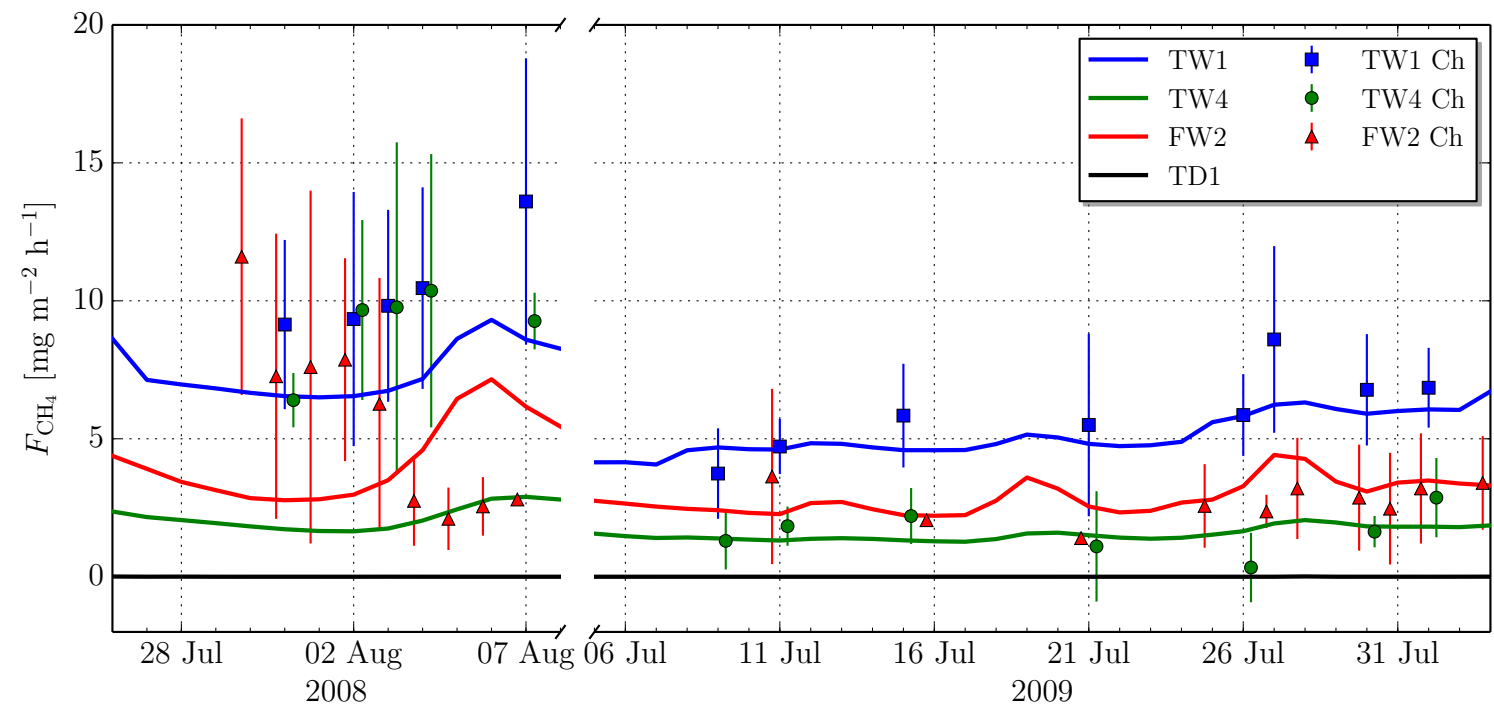

Figure 7. Temporal dynamics of the methane fluxes modelled with PEATLAND-VU and measured with the closed-chamber method for the EC measurement periods in 2008 and 2009. The chamber measurements of TW4 class are shifted $6 \mathrm{~h}$ forward and FW2 class $6 \mathrm{~h}$ backward for clearer indication of the error bars. TW1 is the Eriophorum angustifolium and Carex sp. and Arctophila fulva and Arctagrostis latifolia class, TW4 is the Sphagnum sp. class, and FW2 is the Arctophila fulva and Arctagrostis latifolia class, located on the floodplain.

that class on the vegetation map:

$$
\begin{aligned}
& D=\left|F_{\mathrm{FW}}-F_{\mathrm{AW}}\right|\left(\mathrm{mg} \mathrm{m}^{-2} \mathrm{~h}^{-1}\right), \\
& D_{\mathrm{veg}}=\sum_{i=1}^{3}\left|\frac{\Phi_{i}}{\Omega}-f_{i}\right| \times 100(\%),
\end{aligned}
$$

where $\Phi$ represents the integrated footprint function over the dimensions of the vegetation map for a particular vegetation class, and $i=1-3$ represents the classes TW1, TW4 and FW2.

\section{Results}

\subsection{PEATLAND-VU methane emissions modelling results}

Figure 7 shows the methane fluxes from the PEATLANDVU model for 2008 and 2009. The TD1 class shows nearzero emissions throughout both periods. The TW1 and TW4 classes show little variation in methane emissions during both periods, which is partly explained by a small change in soil temperature and water table (by results of multilinear 

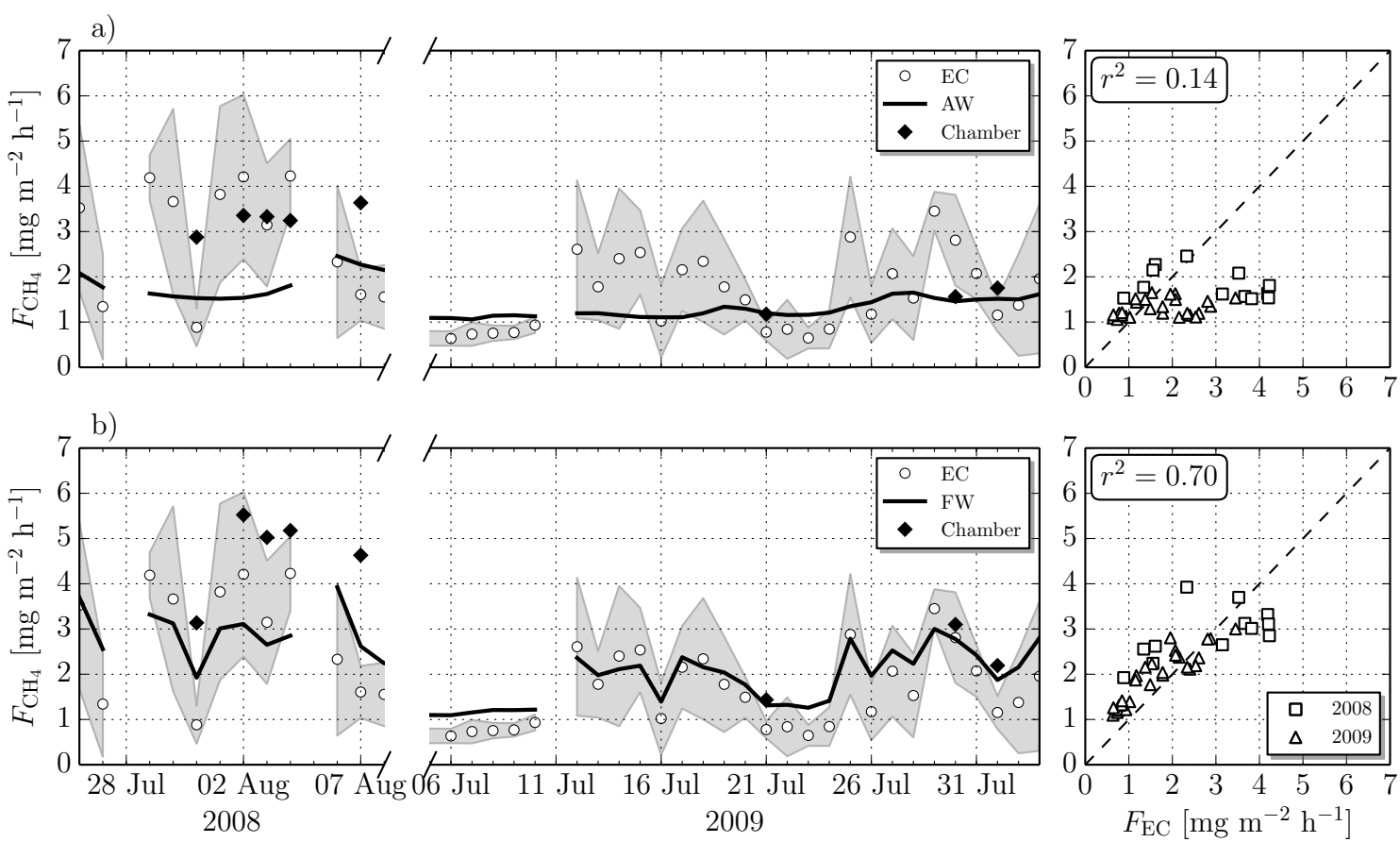

Figure 8. Temporal dynamics of the methane fluxes as measured with the EC system (white circles), modelled calculated fluxes (black lines) and upscaled chamber measurements (black diamonds) using (a) the AW approach and (b) the FW approach for years 2008 and 2009. Shaded areas represent one standard deviation of daily samples of the EC measurements. Scatter plots on the right-hand side show EC flux vs. modelled (a) AW and (b) FW flux comparisons.

regression analysis: $r^{2}=0.64$ and 0.56 for TW1 and TW4, respectively). FW2 shows a strong relationship with soil temperature $\left(r^{2}=0.68\right)$, which slightly improves when water table is added as another predictor $\left(r^{2}=0.73\right)$. The model shows a poor fit to the chamber measurements in 2008 (Fig. 7). The model failed to reproduce the temporal patterns and the magnitude of the emissions from the TW4 and FW2 classes. There are not enough measurements from the TW1 class to draw conclusions on the temporal pattern, although the existing data suggest an underestimation of fluxes by nearly $20 \%$. In 2009 , the model follows the chamber measurements much more closely. Most of the time, the modelled fluxes stay within one standard deviation of the observed values.

\subsection{Evaluation by AW average}

Figure 8a shows a comparison of the methane flux modelled with the PEATLAND-VU model and upscaled using the AW approach and the EC flux observations. Using the AW method to upscale the modelled fluxes yields a low correlation with the EC flux on a daily timescale with $r^{2}=0.14$. The upscaled fluxes do not follow the temporal pattern observed by the EC system, having little variation throughout both seasons. The magnitude of the upscaled flux is noticeably lower than the EC flux. Cumulative modelled emissions during the EC measurement periods in 2008 and 2009 are 0.53 and
$0.87 \mathrm{~g} \mathrm{CH}_{4} \mathrm{~m}^{-2}$, respectively, while the cumulative EC flux shows 0.83 and $1.09 \mathrm{~g} \mathrm{CH}_{4} \mathrm{~m}^{-2}$, respectively for the same periods. Thus, the AW upscaling approach shows $27.4 \%$ lower methane emission when compared to the EC flux.

There were only 8 days in total where chamber measurements were performed on all of the relevant vegetation types during the same day. Daily averages of these measurements were upscaled using the same technique. The magnitude of the upscaled fluxes is close to the EC flux.

\subsection{Evaluation by FW average}

The methane flux modelled with the PEATLAND-VU model and calculated using the FW approach shows a good temporal correlation with the EC flux with $r^{2}=0.7$ (Fig. 8b). The magnitude of the flux is similar to the EC flux. More importantly, however, it also follows the temporal pattern of the EC flux. The cumulative flux for 2008 and 2009 is 0.84 and $1.3 \mathrm{~g} \mathrm{CH}_{4} \mathrm{~m}^{-2}$, respectively, while the cumulative EC flux shows 0.83 and $1.09 \mathrm{~g} \mathrm{CH}_{4} \mathrm{~m}^{-2}$, respectively for the same periods. Therefore, using the FW approach yields slightly higher $(+11.4 \%)$ methane emissions as compared to the EC observations. The fluxes calculated by the FW method using chamber measurements are significantly higher than the EC flux in 2008, but not in 2009 . 


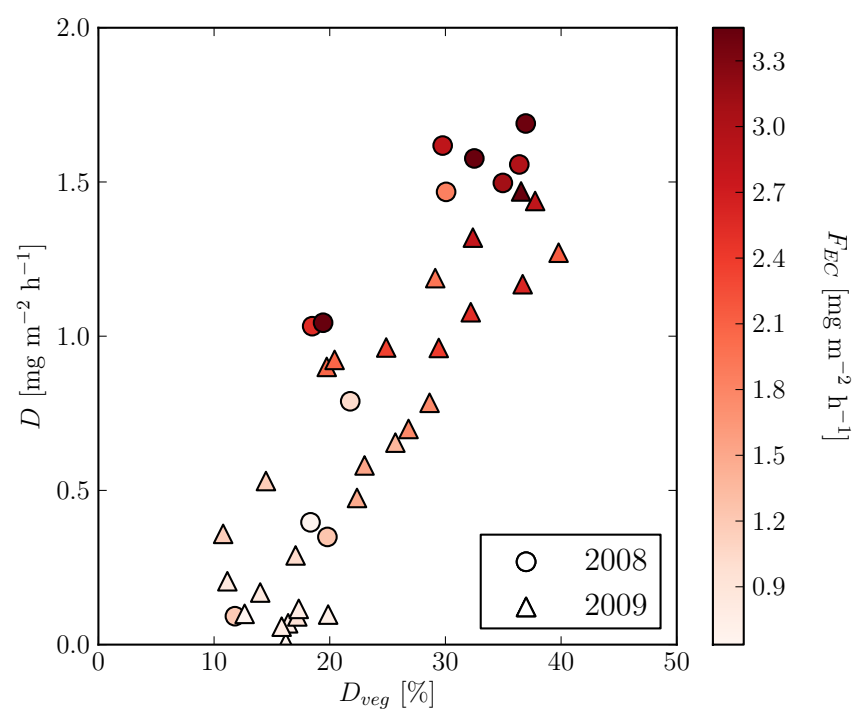

Figure 9. Difference between the calculated fluxes from the two methods $(D)$ vs. "vegetation composition difference" $\left(D_{\mathrm{veg}}\right)$. Colours from white to red show the magnitude of the EC flux.

\subsection{Similarity between the evaluation methods}

The difference between the two evaluation methods becomes minimal, when the "vegetation composition difference" is low (Fig. 9). This result demonstrates the sensor location bias (Schmid and Lloyd, 1999) effect of limited spatial representativeness of the EC measurements. At our validation site, the occurrence of (nearly) non-emitting vegetation types is high and irregularly distributed. Therefore footprint of the EC tower often covers an area with larger contribution by highemitting vegetation types as compared to fractional areas of the vegetation map. This in turn leads to elevated values of fluxes calculated by FW average. In some cases, however, when the contribution of vegetation types as calculated by the footprint model roughly matches the fractional areas of these types on the vegetation map, the fluxes calculated by both methods and the EC flux match as well. This only happened when the EC flux was low, suggesting a high contribution of non-emitting types. Figure 6 illustrates this effect and shows two examples of the modelled footprints. In the first example (31 July 2008) footprints mainly cover the northern sector of the vegetation map which is dominated by non-emitting vegetation types. In the second example (29 July 2009) the northwestern sector is covered by the footprints, which has a relatively high occurrence of high-emitting vegetation types. The difference between the two examples leads to increased difference between $\mathrm{F}_{\mathrm{AW}}$ and $\mathrm{F}_{\mathrm{FW}}$ fluxes.

On larger scales (i.e. when a vegetation map extent is much larger than a typical footprint of an EC tower) this similarity may not hold, as it may not be possible to extrapolate the analysis to other vegetation types and environmental conditions.

\section{Discussion}

\subsection{Evaluation by AW average}

The magnitude of the modelled $\mathrm{CH}_{4}$ flux upscaled by the AW approach was $\sim 27 \%$ lower than the magnitude of the EC observations. The temporal dynamics were also not captured, leading to a low correlation with the EC flux. To explain this, we calculated the contribution of each class to the total upscaled flux. Cumulative contributions are presented in Fig. 10a. The TW1 class dominates the upscaled flux for both study periods, having $67 \%$ contribution on average. TW4 and FW2 classes contribute nearly $15 \%$ each. Variations in the upscaled flux could be explained largely by variations in the soil temperature at $4 \mathrm{~cm}$ depth and the water table $\left(r^{2}=0.61\right)$.

Several reasons may have contributed to the low correlation with the EC flux. Firstly, as the vegetation composition in the EC tower footprint is not taken into account, significant mismatches can be introduced (Hargreaves and Fowler, 1998; Forbrich et al., 2011). In the case of a homogeneous and isotropic vegetation pattern, the consideration of a dynamic footprint will not lead to a significantly different flux. However, when the vegetation pattern is heterogeneous and moreover anisotropic (i.e. not the same in different directions as seen from the EC tower), a dynamic footprint will have a sizeable impact on the measured flux. A changing vegetation composition in the EC tower footprint will change the influence of different vegetation types on the EC flux. The importance of the vegetation distribution (Shannon et al., 1996) and the EC flux footprint consideration (Leclerc and Thurtell, 1990) were recognized almost two decades ago. The latter, however, is still not properly considered, when comparing modelled methane fluxes with EC observations. To mitigate this issue, we present a validation approach, which considers both these phenomena in the next section.

Secondly, as shown previously (Becker et al., 2008; Forbrich et al., 2011), the vegetation map classification may contribute to the mismatches. Since the resolution of the map is $2 \mathrm{~m}$, it is possible that some of the classes might have been over- or underestimated. From field observations, however, it is likely that this inaccuracy will explain only a small portion of the mismatch. Betula nana dwarf shrubs and Salix bushes that form the TD1 class tend to grow in patches on palsa-like formations with radii (linear sizes) larger than $2 \mathrm{~m}$. Therefore, only borders of these patches will be uncertain, largely preserving the surface area of this class. Grasses that comprise the TW1 class have a similar growth pattern, but usually grow in wetter areas. The FW2 class is localized on the floodplain, and consists of large contiguous areas (Fig. 4). It forms two large patches, separated by the small creek with patches of Salix pulchra. We use this class for the whole wet area on the floodplain, despite apparently heterogeneous vegetation. This may not be realistic as van Huissteden et al. (2005) reported high spatial variability of methane fluxes from that 

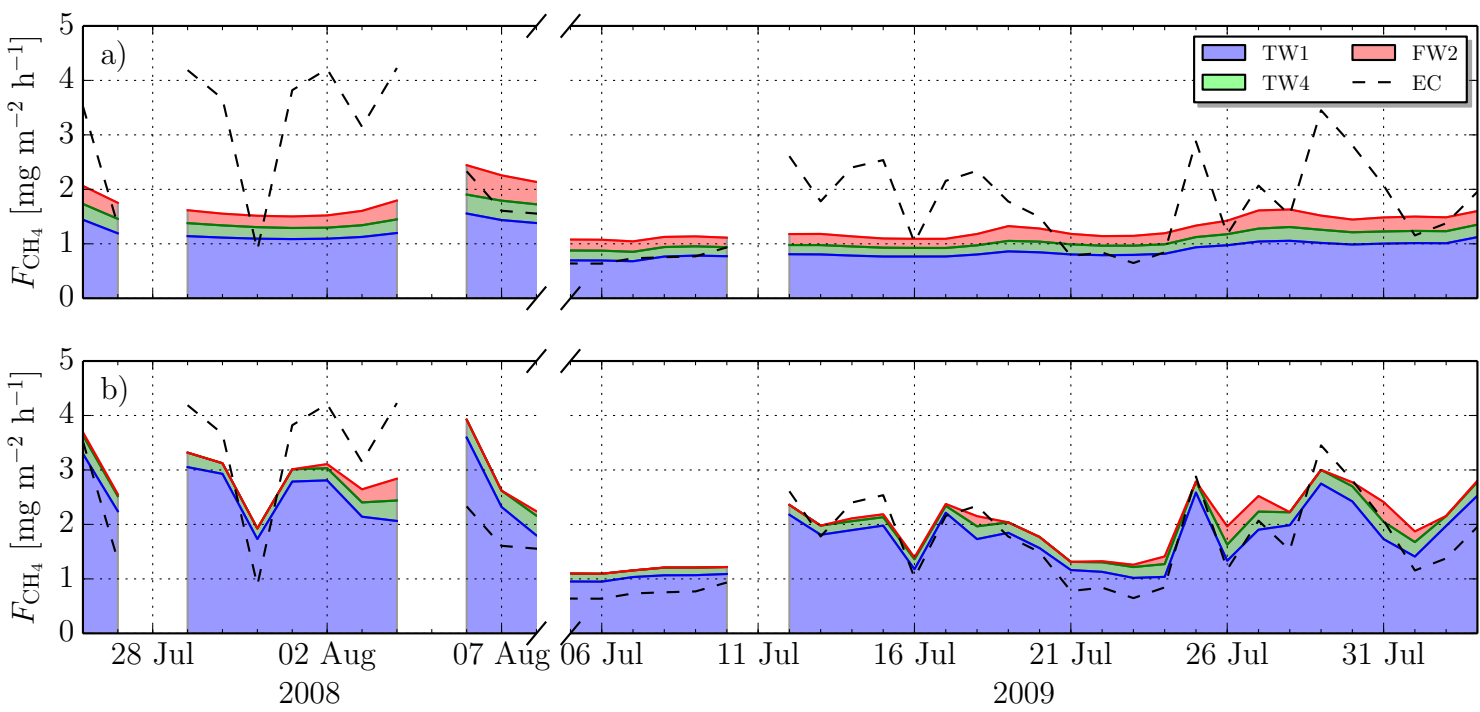

Figure 10. Temporal dynamics of the methane fluxes as measured by the EC system (dashed black lines) and the calculated fluxes of the PEATLAND-VU model using (a) the AW and (b) FW approaches for each class during 2008 and 2009. Contributions from TD1 as well as the River and Lakes class are not shown as they are very close to zero.

area. Hotspots of methane emissions that cannot be recognized on the satellite image due to the limited resolution may exist. Significant uncertainty may also exist in the TW4 class classification, which has a highly heterogeneous pattern. Parmentier et al. (2011) made an assessment of the accuracy of the vegetation map and reported $86.79 \%$ accuracy. This accuracy provides us with confidence that, even with a higher resolution, the distribution of different vegetation types on the map will be largely preserved.

Thirdly, PEATLAND-VU model errors could be a reason for the mismatch; van Huissteden et al. (2009) conducted a model sensitivity analysis with the Generalized Likelihood Uncertainty Estimation (GLUE) method, showing that the model performs noticeably better for the terrace and somewhat worse for the floodplain. Together with the neglected hot spots on the floodplain, it is possible that the emissions from the floodplain are significantly different from the values reported by the model. Another source of error is the lack of spatial variation of the environmental parameters in the model. Currently, the same temperature and water table position measurements, for example, are used to model $\mathrm{CH}_{4}$ fluxes from different classes. In reality, some variation in these parameters exist within each class which is not accounted for in the model. This effect would be more pronounced on a plot scale and will diminish on the ecosystem scale.

\subsection{Evaluation by FW average}

Methane fluxes calculated with the FW approach showed a good correlation with the EC measurements on a daily timescale with $r^{2}=0.7$ (Fig. 8b). Cumulative contributions are presented in Fig. 10b. Contributions from TW1, TW4 and
FW2 generally follow the EC temporal pattern during both years. The TD1 class (comprising nearly half of the map, $48.6 \%$ ) and the River and Lakes class (comprising almost $6 \%$ ) had nearly zero contributions throughout both measurement periods.

In general, using this method leads to a small $(\sim 11.4 \%)$ overestimation of the flux as compared to the EC flux. The calculated flux was close to or within one standard deviation (calculated based on daily samples of the EC measurements) of the EC flux during both years, with a closer fit in 2009.

The magnitude of the three peaks in the EC measurements in 2008 on 29, 30 July, 1, 2 August, and 4 August was not reproduced. As mentioned earlier, this could be the result of model misperformance for the TW4 and FW2 classes as compared to the chamber measurements. The high water table position in 2008 could be the reason for this. Since the model failed to reproduce the magnitude of the fluxes, an underestimation occurs on these days. We hypothesize that a peak in modelled fluxes on 6 August is caused by a peak in soil temperature which occurred on that same day. Interestingly, this behaviour cannot be seen in the EC data on that day. The actual value is very close to one standard deviation of the EC flux however.

An explanation of this mismatch involves the two arguments about the vegetation map classification error and the PEATLAND-VU model performance, that are inherent to both evaluation methods. However, due to the addition of the footprint model to the calculation scheme, the uncertainty of this model also needs to be considered. The exact uncertainty of the footprint model used in this study is unknown as no artificial tracer experiment was conducted to validate it. This is a general problem in footprint modelling 
(Schmid, 2002) because - as stated by Foken and Leclerc (2004) - artificial tracer validation experiments are too expensive. Many validation studies, therefore, compare analytical models to Lagrangian stochastic models, which are in turn compared to Large Eddy Simulation models (Foken and Leclerc, 2004). Another way is to use natural tracer experiments. In one such study (Neftel et al., 2008), it was shown that this particular footprint model performed quite well at a grassland site on the Central Swiss Plateau. Furthermore, the authors suggest that the model still produces usable, semi-qualitative results under a broader range of the stability parameter $(-3<5<+3)$ than used in this study. Considering the similar vegetation height $(\sim 30 \mathrm{~cm})$, we believe it is safe to assume that the model's result represents the "real" flux footprint quite closely.

We showed that this approach is more favourable for the validation of methane emission models with EC observations rather than the AW approach on a daily timescale. Zhang et al. (2012) presented a study on the upscaling of methane fluxes based on the AW approach, and got a poor correlation with their EC measurements. We believe that one of the main reasons behind this mismatch may be the AW upscaling method used in the study. While no changes were made to the data and model configuration, using the FW method for calculation improved the fit dramatically (from 0.14 to 0.7 ). Even though the FW approach requires a footprint model - which has its own sources of uncertainty - this method gives useful insight into the performance of methane emission models.

In our study, the spatial resolution of the satellite image allowed for accurate mapping of highly heterogeneous vegetation patterns. The AW method, however, produced a cumulative methane emission estimate, which is $\sim 27 \%$ lower than that measured by the EC system. However, when using the FW method the difference between the calculated flux and the EC flux is $\sim 11 \%$ higher, and can be associated with the methane emission model error, footprint model error, map accuracy, or other unaccounted phenomena. Constraining these uncertainties will provide further insight into major sources of error and will allow for more accurate validation of plot-scale data sets.

The poor match between the AW average flux and FW average flux can be explained by sensor location bias. Changing spatial representativeness of the EC measurements due to dynamic footprint leads to a greater variability in FW average fluxes owing to changing wind direction and atmospheric stability. Therefore, it is not appropriate to compare dynamic EC measurements to fluxes upscaled by AW average, which are calculated based on constant fractional areas of different vegetation types and plot-scale methane emissions.

The detailed analysis of the EC footprint for upscaling methane fluxes in ecosystems with high spatial heterogeneity to ecosystem scale has been recently recognized as necessary (Sachs et al., 2010; Nicolini et al., 2013), but is still not being carried out in some studies (Sun et al., 2013).

\section{Conclusions}

Methane fluxes calculated with the footprint-weighted average approach were shown to be of the same magnitude as the EC flux with a small overestimation (by $11.4 \%$ ). The temporal pattern of the EC flux on a daily timescale was captured, with $r^{2}=0.7$. Most of the variations in the calculated flux could be explained through a changing EC flux footprint and therefore a changing vegetation distribution within the footprint. This approach is more appropriate for model validation using EC measurements, especially for sites with a heterogeneous and irregular vegetation pattern, as it takes into account the vegetation composition in the $\mathrm{EC}$ tower footprint.

Since the area-weighted upscaling lacks this dynamic spatial and temporal information, it is unsurprising that this approach failed to reproduce the temporal dynamics of the EC flux, which led to a low correlation with $r^{2}=0.14$, and a $27.4 \%$ lower estimate of methane emissions. The variations in modelled and upscaled fluxes from different classes could be largely explained by variations in soil temperature at depth of $4 \mathrm{~cm}$ and water table position $\left(r^{2}=0.61\right)$.

The PEATLAND-VU model was able to capture not only the magnitude of the EC flux, but also the temporal dynamics on a daily timescale when the FW approach was used. This confirms that the model performs well as compared to EC measurements and makes it possible to use the model for upscaling of methane fluxes to larger spatial scales, provided that a suitable vegetation map is available.

Acknowledgements. This study was funded by the Darwin Center for Biogeosciences (project no. 142.16.3051). The contribution by G. Schaepman-Strub was supported by the University of Zurich Research Priority Program "Global Change and Biodiversity". The authors are grateful to Lars Kutzbach and the anonymous referee for their comments and suggestions. The authors would also like to thank the developers of matplotlib library (Hunter, 2007).

Edited by: A. Neftel

\section{References}

Aubinet, M., Grelle, A., Ibrom, A., Rannik, Ü., Moncrieff, J., Foken, T., Kowalski, A. S., Martin, P. H., Berbigier, P., Bernhofer, Ch., Clement, R., Elbers, J., Granier, A., Grünwald, T., Morgenstern, K., Pilegaard, K., Rebmann C., Snijders, W., Valentini, R., and Vesala, T.: Estimates of the annual net carbon and water exchange of forests: the EUROFLUX methodology., Adv. Ecol. Res., 30, 113-175, 2000.

Aubinet, M., Vesala, T., and Papale, D.: Eddy covariance: a practical guide to measurement and data analysis, Springer, Dordrecht, the Netherlands, 2012.

Baldocchi, D. D.: Assessing the eddy covariance technique for evaluating carbon dioxide exchange rates of ecosystems: past, present and future, Glob. Change Biol., 9, 479-492, 2003.

Becker, T., Kutzbach, L., Forbrich, I., Schneider, J., Jager, D., Thees, B., and Wilmking, M.: Do we miss the hot spots? - 
The use of very high resolution aerial photographs to quantify carbon fluxes in peatlands, Biogeosciences, 5, 1387-1393, doi:10.5194/bg-5-1387-2008, 2008.

Bekki, S. and Law, K. S.: Sensitivity of the atmospheric $\mathrm{CH}_{4}$ growth rate to global temperature changes observed from 1980 to 1992 , Tellus B, 49, 409-416, 1997.

Bubier, J. L.: The relationship of vegetation to methane emission and hydrochemical gradients in northern peatlands, J. Ecol., 83, 403-420, 1995.

Cao, M., Marshall, S., and Gregson, K.: Global carbon exchange and methane emissions from natural wetlands: application of a process-based model, J. Geophys. Res., 101, 14399-14414, 1996.

Christensen, T. R., Prentice, I. C., Kaplan, J., Haxeltine, A., and Sitch, S.: Methane flux from northern wetlands and tundra, Tellus B, 48, 652-661, 1996.

Christensen, T. R., Johansson, T., Åkerman, H. J., Mastepanov, M., Malmer, N., Friborg, T., Crill, P., and Svensson, B. H.: Thawing sub-arctic permafrost: effects on vegetation and methane emissions, Geophys. Res. Lett., 31, L04501, doi:10.1029/2003GL018680, 2004.

Foken, T. and Leclerc, M. Y.: Methods and limitations in validation of footprint models, Agr. Forest Meteorol., 127, 223-234, 2004.

Forbrich, I., Kutzbach, L., Wille, C., Becker, T., Wu, J., and Wilmking, M.: Cross-evaluation of measurements of peatland methane emissions on microform and ecosystem scales using high-resolution landcover classification and source weight modelling, Agr. Forest Meteorol., 151, 864-874, 2011.

Granberg, G., Grip, H., Löfvenius, M. O., Sundh, I., Svensson, B., and Nilsson, M.: A simple model for simulation of water content, soil frost, and soil temperatures in boreal mixed mires, Water Resour. Res., 35, 3771-3782, 1999.

Hargreaves, K. J. and Fowler, D.: Quantifying the effects of water table and soil temperature on the emission of methane from peat wetland at the field scale, Atmos. Environ., 32, 3275-3282, 1998.

Haxeltine, A., Prentice, I. C., and Creswell, I. D.: A coupled carbon and water flux model to predict vegetation structure, J. Veg. Sci., 7, 651-666, 1996.

Hendriks, D. M. D., Dolman, A. J., van der Molen, M. K., and van Huissteden, J.: A compact and stable eddy covariance set-up for methane measurements using off-axis integrated cavity output spectroscopy, Atmos. Chem. Phys., 8, 431-443, doi:10.5194/acp-8-431-2008, 2008.

Hinkel, K. M., Eisner, W. R., Bockheim, J. G., Nelson, F. E., Peterson, K. M., and Dai, X.: Spatial extent, age, and carbon stocks in drained thaw lake basins on the Barrow Peninsula, Alaska, Arct. Antarct. Alp. Res., 35, 291-300, 2003.

Høstrup, J.: A simple model for the adjustment of velocity spectra in unstable conditions downstream of an abrupt change in roughness and heat flux, Bound.-Lay. Meteorol., 21, 341-356, 1981.

Hunter, J. D.: Matplotlib: a 2-D graphics environment, Comput. Sci. Eng., 9, 90-95, 2007.

Kaimal, J. C., Wyngaard, J. C., Izumi, Y., and Coté, O. R.: Spectral characteristics of surface-layer turbulence, Q. J. R. Meteorol. Soc., 98, 563-589, 1972.

Kellner, E., Baird, A. J., Oosterwoud, M., Harrison, K., and Waddington, J. M.: Effect of temperature and atmospheric pressure on methane $\left(\mathrm{CH}_{4}\right)$ ebullition from near-surface peats, Geophys. Res. Lett., 33, L18405, doi:10.1029/2006GL027509, 2006.
Kim, J., Verma, S. B., Billesbach, D. P., and Clement, R. J.: Diel variation in methane emission from a midlatitude prairie wetland: significance of convective throughflow in Phragmites australis, J. Geophys. Res.-Atmos., 103, 28029-28039, 1998.

Kling, G. W., Kipphut, G. W., and Miller, M. C.: The flux of $\mathrm{CO}_{2}$ and $\mathrm{CH}_{4}$ from lakes and rivers in arctic Alaska, Hydrobiologia, 240, 23-36, 1992.

Kormann, R. and Meixner, F. X.: An analytical footprint model for non-neutral stratification, Bound.-Lay. Meteorol., 99, 207-224, 2001.

Kutzbach, L., Wagner, D., and Pfeiffer, E.-M.: Effect of microrelief and vegetation on methane emission from wet polygonal tundra, Lena Delta, northern Siberia, Biogeochemistry, 69, 341-362, 2004.

Leclerc, M. Y. and Thurtell, G. W.: Footprint prediction of scalar fluxes using a Markovian analysis, Bound.-Lay. Meteorol., 52, 247-258, 1990.

Mi, Y., van Huissteden, J., Parmentier, F. J. W., Gallagher, A., Budishchev, A., Berridge, C. T., and Dolman, A. J.: Improving a plot-scale methane emission model and its performance at a northeastern Siberian tundra site, Biogeosciences, 11, 39853999, doi:10.5194/bg-11-3985-2014, 2014.

Moore, C. J.: Frequency response corrections for eddy correlation systems, Bound.-Lay. Meteorol., 37, 17-35, 1986.

Nakai, T., van der Molen, M. K., Gash, J. H. C., and Kodama, Y.: Correction of sonic anemometer angle of attack errors, Agr. Forest Meteorol., 136, 19-30, 2006.

Neftel, A., Spirig, C., and Ammann, C.: Application and test of a simple tool for operational footprint evaluations, Environ. Pollut., 152, 644-652, 2008.

Nicolini, G., Castaldi, S., Fratini, G., and Valentini, R.: A literature overview of micrometeorological $\mathrm{CH}_{4}$ and $\mathrm{N}_{2} \mathrm{O}$ flux measurements in terrestrial ecosystems, Atmos. Environ., 81, 311-319, 2013.

Parmentier, F. J. W., van Huissteden, J., van der Molen, M. K., Schaepman-Strub, G., Karsanaev, S. A., Maximov, T. C., and Dolman, A. J.: Spatial and temporal dynamics in eddy covariance observations of methane fluxes at a tundra site in northeastern Siberia, J. Geophys. Res.-Biogeo., 116, G03016, doi:10.1029/2010JG001637, 2011.

Riutta, T., Laine, J., Aurela, M., Rinne, J., Vesala, T., Laurila, T., Haapanala, S., Pihlatie, M., and Tuittila, E.-S.: Spatial variation in plant community functions regulates carbon gas dynamics in a boreal fen ecosystem, Tellus B, 59, 838-852, 2007.

Ryan, W. B. F., Carbotte, S. M., Coplan, J. O., O'Hara, S., Melkonian, A., Arko, R., Weissel, R. A., Ferrini, V., Goodwillie, A., Nitsche, F., Bonczkowski, J., and Zemsky, R.: Global multiresolution topography synthesis, Geochem. Geophy. Geosy., 10, Q03014, doi:10.1029/2008GC002332, 2009.

Sachs, T., Wille, C., Boike, J., and Kutzbach, L.: Environmental controls on ecosystem-scale $\mathrm{CH}_{4}$ emission from polygonal tundra in the Lena River Delta, Siberia, J. Geophys. Res.-Biogeo., 113, G00A03, doi:10.1029/2007JG000505, 2008.

Sachs, T., Giebels, M., Boike, J., and Kutzbach, L.: Environmental controls on $\mathrm{CH}_{4}$ emission from polygonal tundra on the microsite scale in the Lena river delta, Siberia, Glob. Change Biol., 16, 3096-3110, 2010. 
Schmid, H. P.: Footprint modeling for vegetation atmosphere exchange studies: a review and perspective, Agr. Forest Meteorol., 113, 159-183, 2002.

Schmid, H. P. and Lloyd, C. R.: Spatial representativeness and the location bias of flux footprints over inhomogeneous areas, Agr. Forest Meteorol., 93, 195-209, 1999.

Schrier-Uijl, A. P., Kroon, P. S., Hensen, A., Leffelaar, P. A., Berendse, F., and Veenendaal, E. M.: Comparison of chamber and eddy covariance-based $\mathrm{CO}_{2}$ and $\mathrm{CH}_{4}$ emission estimates in a heterogeneous grass ecosystem on peat, Agr. Forest Meteorol., $150,825-831,2010$.

Shannon, R. D., White, J. R., Lawson, J. E., and Gilmour, B. S.: Methane efflux from emergent vegetation in peatlands, J. Ecol., 84, 239-246, 1996.

Shurpali, N. J., Verma, S. B., Clement, R. J., and Billesbach, D. P.: Seasonal distribution of methane flux in a Minnesota peatland measured by eddy correlation, J. Geophys. Res.-Atmos., 98, 20649-20655, 1993.

Simpson, I. J., Edwards, G. C., Thurtell, G. W., den Hartog, G., Neumann, H. H., and Staebler, R. M.: Micrometeorological measurements of methane and nitrous oxide exchange above a boreal aspen forest, J. Geophys. Res.-Atmos., 102, 29331-29341, 1997.

Sitch, S., Smith, B., Prentice, I. C., Arneth, A., Bondeau, A., Cramer, W., Kaplan, J. O., Levis, S., Lucht, W., Sykes, M. T., Thonicke, K., and Venevsky, S.: Evaluation of ecosystem dynamics, plant geography and terrestrial carbon cycling in the LPJ dynamic global vegetation model, Glob. Change Biol., 9, 161-185, 2003.

Striegl, R. G., Dornblaser, M., McDonald, C., Rover, J., and Stets, E.: Carbon dioxide and methane emissions from the Yukon River system, Global Biogeochem. Cy., 26, GB0E05, doi:10.1029/2012GB004306, 2012.

Ström, L., Ekberg, A., Mastepanov, M., and Røjle Christensen, T.: The effect of vascular plants on carbon turnover and methane emissions from a tundra wetland, Glob. Change Biol., 9, 11851192, 2003.

Sun, L., Song, C., Miao, Y., Qiao, T., and Gong, C.: Temporal and spatial variability of methane emissions in a northern temperate marsh, Atmos. Environ., 81, 356-363, 2013.

Turetsky, M. R., Wieder, R. K., and Vitt, D. H.: Boreal peatland $\mathrm{C}$ fluxes under varying permafrost regimes, Soil Biol. Biochem., 34, 907-912, 2002.

van der Molen, M. K., van Huissteden, J., Parmentier, F. J. W., Petrescu, A. M. R., Dolman, A. J., Maximov, T. C., Kononov, A. V., Karsanaev, S. V., and Suzdalov, D. A.: The growing season greenhouse gas balance of a continental tundra site in the Indigirka lowlands, NE Siberia, Biogeosciences, 4, 985-1003, doi:10.5194/bg-4-985-2007, 2007.

van Huissteden, J., Maximov, T. C., and Dolman, A. J.: High methane flux from an arctic floodplain (Indigirka lowlands, eastern Siberia), J. Geophys. Res.-Biogeo., 114, G02002, doi:10.1029/2005JG000010, 2005. van Huissteden, J., van den Bos, R., and Alvarez, I. M.: Modelling the effect of water-table management on $\mathrm{CO}_{2}$ and $\mathrm{CH}_{4}$ fluxes from peat soils, Neth. J. Geosci., 85, 3-18, 2006.

van Huissteden, J., Petrescu, A. M. R., Hendriks, D. M. D., and Rebel, K. T.: Sensitivity analysis of a wetland methane emission model based on temperate and arctic wetland sites, Biogeosciences, 6, 3035-3051, doi:10.5194/bg-6-3035-2009, 2009.

Walter, B. P. and Heimann, M.: A process-based, climate-sensitive model to derive methane emissions from natural wetlands: application to five wetland sites, sensitivity to model parameters, and climate, Global Biogeochem. Cy., 14, 745-765, 2000.

Walter, B. P., Heimann, M., and Matthews, E.: Modeling modern methane emissions from natural wetlands: 1 . Model description and results, J. Geophys. Res.-Atmos., 106, 34189-34206, 2001.

Wania, R., Ross, I., and Prentice, I. C.: Implementation and evaluation of a new methane model within a dynamic global vegetation model: LPJ-WHyMe v1.3.1, Geosci. Model Dev., 3, 565-584, 2010 .

Webb, E. K., Pearman, G. I., and Leuning, R.: Correction of flux measurements for density effects due to heat and water vapour transfer, Q. J. Royal Meteorol. Soc., 106, 85-100, 1980.

Wessel, P. and Smith, W. H.: A global, self-consistent, hierarchical, high-resolution shoreline database, J. Geophys. Res., 101, 87418743, 1996.

Wille, C., Kutzbach, L., Sachs, T., Wagner, D., and Pfeiffer, E.-M.: Methane emission from Siberian arctic polygonal tundra: eddy covariance measurements and modeling, Glob. Change Biol., 14, 1395-1408, 2008.

Yurova, A., Wolf, A., Sagerfors, J., and Nilsson, M.: Variations in net ecosystem exchange of carbon dioxide in a boreal mire: modeling mechanisms linked to water table position, J. Geophys. Res.-Biogeo., 112, G02025, doi:10.1029/2006JG000342, 2007.

Zhang, Y., Sachs, T., Li, C., and Boike, J.: Upscaling methane fluxes from closed chambers to eddy covariance based on a permafrost biogeochemistry integrated model, Glob. Change Biol., 18, 1428-1440, 2012.

Zhuang, Q., Melillo, J. M., Kicklighter, D. W., Prinn, R. G., McGuire, A. D., Steudler, P. A., Felzer, B. S., and Hu, S.: Methane fluxes between terrestrial ecosystems and the atmosphere at northern high latitudes during the past century: a retrospective analysis with a process-based biogeochemistry model, Global Biogeochem. Cy., 18, GB3010, doi:10.1029/2004GB002239, 2004.

Zona, D., Oechel, W. C., Kochendorfer, J., Paw, U., K. T., Salyuk, A. N., Olivas, P. C., Oberbauer, S. F., and Lipson, D. A.: Methane fluxes during the initiation of a large-scale water table manipulation experiment in the Alaskan Arctic tundra, Global Biogeochem. Cy., 23, GB2013, doi:10.1029/2009GB003487, 2009. 